\title{
The evaluation of financial expenditure on public cultural services in Central China
}

\author{
Siyu Liu, Xiyu Liu* \\ School of Economics and Management, Inner Mongolia university of Science and Technology, \\ Baotou Street 7, China \\ 1539782800@qq.com,xiyuLiu@163.com \\ *corresponding author
}

Keywords: Public cultural services, Expenditure efficiency, Equalization, Influencing factors

Abstract: Based on the panel data of six provinces in central China from 2013 to 2017, this paper uses the DEA-Tobit two-step method to measure the efficiency of financial expenditures on public cultural services in six provinces in the central region, and analyzes the factors affecting the efficiency of financial expenditure on cultural services. First, non-parametric data envelopment analysis (DEA) was used to evaluate the efficiency of public cultural expenditures in the central region. In the second phase, a restricted-independent variable regression model (Tobit) was used to achieve an empirical study on the efficiency of consumption and its influencing factors. The study found that the overall level of efficiency of financial expenditures for public cultural services of local governments in the central region is low, and there are significant differences, with uneven efficiency. The per capita GDP, fiscal expenditure structure, government size, population density, cultural policies and education level of residents, economic and social factors are important reasons for this difference in efficiency. Therefore, based on theoretical exploration and empirical results, we finally discussed measures to improve the efficiency of local fiscal public cultural service expenditures in Central China, and put forward countermeasures for the effective provision of public cultural service.

\section{Introduction}

The role of cultural soft power has become more prominent in the era of knowledge-based culture, and the development of culture requires the financial support of the state. Although governments at all levels have spent more and more on culture in recent years, there has been no standard evaluation of the effect of expenditure. The government only blindly increased the input, but did not investigate the basic situation of public culture in the region. Without understanding the local situation, blind investment resulted in the waste of investment funds, which naturally affected the quality of public service provision in China. In the context of economic globalization, the essence of the competition in national economies is the competition of the value of public goods. Therefore, the efficiency evaluation of public culture can propose targeted solutions according to 
the problems found in the research, and ${ }^{1}$ eliminate the emergence of low efficiency from the root, so as to improve the quality of public service delivery in China, which is conducive to improving the discourse power of Chinese culture in the world and realizing cultural power. At the same time, to achieve scientific development and social harmony, it needs strong spiritual support and good cultural conditions, which puts forward new requirements for the provision and resource allocation of public cultural products. At present, the provision of public culture in China lags behind in the process of total growth of fiscal and public expenditure and structural optimization, and there are significant differences between urban and rural areas and regions in the pattern of benefits ${ }^{[6]}$. Most of the domestic scholars have conducted researches on the efficiency of all provinces nationwide, but the efficiency evaluation of local areas is relatively less. Although some scholars have done research on the western and central regions, they are not rational in the selection of evaluation indicators and lack of overall reliability. Moreover, it is only a simple efficiency analysis without taking into account the influence of other factors on efficiency, which needs further testing and exploration. Therefore, the insufficiency of domestic research on this aspect cannot provide theoretical guidance for the financial supply efficiency of regional public cultural services in the future. Therefore, it is of great theoretical significance to evaluate the efficiency of public cultural services in the central region.

\section{Literature Review}

Foreign research on the efficiency of public service is mainly based on the exploration of policy system, equalization of service, diversified integration and public service motivation.

(1) Policy system: Aaberge R and Langorgen A (2006) aim to study the impact of local physical interests on Norway's income distribution, and find that the (marginal) distribution of the city's physical benefits is quite high. Contributing to the inequality in the distribution of in-kind welfare in the city, income (cash) tax plus city-level income have an impact on the provision of public services, and it also proves that the provision of public services has a similar neutral condition (Aaberge R, Langørgen A,2006). TI-FU A (2007) believes that the government has a lack of responsibilities in the provision of education, health, social security and social welfare in public services, and points out that the mechanism of public service loss is the ability and responsibility of the financial asymmetry lower level government (TI-FU A,2007). Accordingly, Qian J (2017) also believes that policy design is important, and that high policy capacity is necessary for social policy development. It was found that under the policy design, the government's policy capacity was significantly enhanced, policy initiatives and fiscal capacity were improved as well (Qian J,2017).

(2) Equalization of public service: Yi-hua L (2008) proposed that the goal of building a harmonious society is based on the basic public services in urban and rural areas (Yi-hua L,2008). Also holding similar views are $\mathrm{Li} \mathrm{B,} \mathrm{Li} \mathrm{T} \mathrm{and} \mathrm{Yu} \mathrm{M} \mathrm{(2017),} \mathrm{who} \mathrm{argued} \mathrm{that} \mathrm{governments} \mathrm{and} \mathrm{the}$ public in developing countries must face regional differences that challenge the economy and public administration (Li B, Li T, Yu M,2017).

(3) In terms of the integration of multiple mechanisms, jian-dong Y I (2012) believes that in the context of China's economic transition, social transformation, cultural transformation and the strengthening of government's public service function, the provision of China's sports public service is urgent and realistic. The most important thing is to provide a good legal environment for sports public services, which requires the establishment of a relatively complete basic sports public service legal system (Jian-dong Y I,2012). At the same time, JIANG X and SHE L (2006) also feel that the provision of public services is not only the responsibility of the government; it should be coordinated by the diversified entities. The public cultural service system should promote 
marketization, especially on the basis of public welfare, to a certain degree of marketization, that is, the integration of public mechanisms and market mechanisms (JIANG X, SHE L, 2006).

(4) Public services motivation: Many studies focus on finding and explaining the antecedents, correlations, and outcomes of Public Service Motivation (PSM), but few people know the impact of national context on individual PSM. Previous studies have shown that national culture may have an independent impact on an individual's PSM. Kim S (2017) examines PSM as a personal-level variable related to national culture, represented by the cultural dimension of Hofstede. He studied the relationship between cultural dimensions and individual PSMs using data from the International Social Survey Program (2005).The results demonstrate that resilience and laissez-faire are positively correlated with individual PSM, while individualism is negatively correlated with individual PSM. However, power distance and uncertainty avoidance have no significant relationship with (PSM Kim S, 2017). This shows that the emergence of public service motives is closely related to national culture and personal traits, and has a mutually reinforcing relationship.

\section{Principles of the Dea Evaluation Model}

In 1978, the concept of DEA was proposed by American operations researchers such as Charnes, Coopor, and Rhodes. In the DEA model, the decision-making unit refers to "department” or "unit”, and the main task of the model is to study the relative validity of the decision elements with several inputs and outputs. The method used is mathematical programming. This model is unique and has been widely used. Its most basic models are CCR and BCC.

\subsection{CCR model based on scale return constant}

Under the premise of constant return on scale, the technical efficiency evaluated by the CCR model is affected by the scale efficiency, so it is also called comprehensive technical efficiency. The decision-making unit (DMU) in DEA refers to the objects to measure the efficiency input and output, specifically, those departments and units.

Table 1 Relevant variable representations and ranges

\begin{tabular}{cccccc}
\hline Meaning & $\begin{array}{c}\text { DMU's technical } \\
\text { efficiency(n) }\end{array}$ & Investment(m) & $\begin{array}{c}\text { Investment } \\
\text { weights }\end{array}$ & Output(q) & $\begin{array}{c}\text { Output } \\
\text { weights }\end{array}$ \\
\hline $\begin{array}{c}\text { Expression } \\
\text { Range }\end{array}$ & $\begin{array}{c}\mathrm{DMU}_{\mathrm{j}} \\
\mathrm{j}=1,2, \cdots, \mathrm{n}\end{array}$ & $\mathrm{x}_{\mathrm{i}}$ & $\mathrm{v}_{\mathrm{i}}$ & $\mathrm{y}_{\mathrm{r}}$ & $\mathrm{u}_{\mathrm{r}}$ \\
$\mathrm{i}=1,2, \cdots, \mathrm{m}$ & $\mathrm{r}=1,2, \cdots, \mathrm{q}$ \\
\hline
\end{tabular}

In the DEA model, if there are only a few decision-making units, then the determined frontier surface is not accurate. The possibility that the segment and the coordinate axis are parallel to each other in the region generated by the decision-making unit mapping is more likely to cause the problem of relaxation occurs. In view of this phenomenon, the relaxation variable $s^{+}$and the remaining variable $s^{-}$need to be further introduced to obtain the following programming formula after adding the relaxation variable: 


$$
\left\{\begin{array}{c}
\min \theta \\
\text { s.t. } \sum_{j=1}^{n} \lambda_{j} x_{i j}+s_{i}^{+}=\theta x_{i k} \\
\sum_{j=1}^{n} \lambda_{j} y_{r j}-s_{r}^{-}=y_{r k} \\
\lambda \geq 0 ; s^{-} \leq 0 ; s^{+} \geq 0 \\
i=1,2, \cdots, m ; \mathrm{r}=1,2, \cdots, q ; j=1,2, \cdots n
\end{array}\right.
$$

\subsection{BCC model based on variable scale returns}

The BBC model established on the basis of variable revenue is called "pure technical efficiency (PTE)" due to the absence of the interference of scale. Compared with CCR dual model, the model has a condition $-\sum_{j=1}^{n} \lambda_{j}=1(\lambda \geq 0)$, after it ensures that the projection of the scale of production and study of decision-making units by the scale of production at the same level.

$$
\left\{\begin{array}{c}
\min \left[\theta-\varepsilon\left(\sum_{i=1}^{m} s_{i}^{-}+\sum_{r=1}^{q} s_{r}^{+}\right)\right] \\
\text {s.t. } \sum_{j=1}^{n} \lambda_{j} x_{i j}+s_{i}^{-} \leq \theta x_{i k} \\
\sum_{j=1}^{n} \lambda_{j} y_{r j}-s_{r}^{+} \geq y_{r k} \\
\sum_{j=1}^{n} \lambda_{j}=1 \\
\lambda \geq 0, s_{r}^{+} \geq s_{i}^{-} \geq 0 \\
i=1,2, \cdots, m ; r=1,2, \cdots, q ; j=1,2, \cdots, n
\end{array}\right.
$$

Where $\theta$ represents the index obtained by the efficiency evaluation; $\varepsilon$ is the well-known Archimedes infinitesimal amount; the combination coefficient is represented by $\lambda_{j}$ When the index is 1 , the DEA of this decision-making unit is valid, and when the index is smaller, the decision-making unit is invalid.

A dual programming expression expressed using the BCC model: 


$$
\left\{\begin{array}{c}
\max \sum_{r=1}^{s} \mu_{r} y_{r k}-\mu_{o} \\
\text { s.t. } \sum_{r=1}^{q} \mu_{r} y_{r j}-\sum_{i=1}^{m} v_{i} x_{i j}-\mu_{o} \\
\sum_{i=1}^{m} v_{i} x_{i k}=1 \\
v \geq 0 ; \mu \geq 0 ; u_{o} \text { free } \\
i=1,2, \cdots, m ; r=1,2, \cdots, q ; j=1,2, \cdots, n
\end{array}\right.
$$

\section{Evaluation of the Efficiency of Public Expenditure on Public Cultural Services in the} Central Region

China's fiscal system is still improving, and the concept of government administration is constantly being explored. The past financial work is centered on income management, but currently the focus of management has shifted to expenditures. Thus more and more people has now started to study on how to calculate the efficiency of fiscal expenditure effectively and reliably. Up to now, the methods for analyzing this efficiency from quantitative aspects include: the analysis of the principal components of the elements, the analysis of the data hierarchy, the analysis using fuzzy mathematics and method of creating DEA model.

\subsection{Selection and description of indicators}

\subsubsection{Principles for selecting indicators}

In order to make the results of performance evaluation authentic and reliable, some principles should be used as a measurement criteria to get closer to the ultimate goal when selecting indicators. The principles currently followed are as follows:

(1) Indicators need to be related to each other.

(2) The selected indicators should be comprehensive.

(3) The measurement with this indicator can be calculated and implemented.

(4) To select more important indicators.

(5) Indicators should be dynamic and must be adjusted according to actual conditions.

It is not hard to see that the determination principle of evaluation indicators is SMART standard around performance evaluation (Specific specificity, Measurable measurability, Attainable achievability, Realistic reality, Time bound time limit), at the same time in order to meet the demand of the masses culture, realize the cultural rights and interests of the people as the center and extended, on the basis of the scientific and reasonable to set covers the major aspects of public cultural services index system and comprehensive reflection of public cultural services input, output, quantity, quality, running state and so on.

\subsubsection{Description of indicator}

(1) Data source. In this study, the selected research area is the six provinces in the central region. The research object is the efficiency of the financial expenditures of these provinces in public 
culture. This paper takes the local financial public cultural service system of these six provinces as six decision-making units to evaluate its efficiency. Avoid the impact of accidental factors as much as possible, and select data of consecutive and complete recent years (2013-2017). The data mainly comes from: <China Statistical Yearbook>, <China Library Yearbook>, <China Financial Yearbook>, <China Cultural Relics Statistical Yearbook> and the statistical yearbooks of these provinces in recent years. The model used in this study is the DEA model, which has an input-oriented mathematical model that can have multiple inputs and outputs and is suitable for the efficiency calculation of fiscal expenditures in the central region in terms of public culture.

(2) Index selection. The funds to build public facilities and meet people's cultural needs in China are mainly appropriated by finance. Public cultural services cover a wide range of fields - film and television resources, paper books, museums, archives, etc. This paper selects the four most representative fields - cultural property, library, mass culture and public art. This paper selects the four most representative fields - cultural relic industry, library, mass culture industry and public art industry. Most of the construction funds for public facilities and cultural services are in these aspects, so the comprehensive indicators can be ensured. We use the cultural undertaking fee instead of the theoretical public cultural investment, because this piece has not been accounted for separately.

(3) Description of indicators. The evaluation index system of government financial expenditure efficiency of public cultural services constructed in this paper is shown in Table 2 below.

Table 2 Evaluation Index System of Financial Expenditure Efficiency of Public Cultural Services

\begin{tabular}{|c|c|c|}
\hline The index & Input index & Output index \\
\hline $\begin{array}{l}\text { Financial investment in } \\
\text { public cultural services }\end{array}$ & $\begin{array}{c}\text { Per capita cultural business } \\
\text { expenses }\end{array}$ & $\begin{array}{l}\text { Integrated public } \\
\text { cultural } \\
\text { service output } \\
\text { Total }\end{array}$ \\
\hline Public library service & $\begin{array}{l}\text { Number of libraries } \\
\text { Number of employees in the library }\end{array}$ & $\begin{array}{l}\text { circulation of } \\
\text { the library } \\
\text { Library exhibitions }\end{array}$ \\
\hline Public museum service & $\begin{array}{l}\text { Number of museums } \\
\text { Number of employees in the } \\
\text { museum }\end{array}$ & $\begin{array}{l}\text { Museum visits } \\
\text { Museum } \\
\text { held exhibitions } \\
\text { Number Of }\end{array}$ \\
\hline Mass culture service & $\begin{array}{l}\text { Number of mass cultural } \\
\text { institutions } \\
\text { Number of employees in mass } \\
\text { cultural institutions }\end{array}$ & $\begin{array}{l}\text { trainings organized } \\
\text { by mass cultural } \\
\text { institutions } \\
\text { Training of mass } \\
\text { cultural institutions }\end{array}$ \\
\hline
\end{tabular}

\subsection{Estimation of Financial Expenditure Efficiency of Public Cultural Services Based on DEA}

The efficiency of local government spending in the public culture can be from both configuration and production. It is specifically divided into comprehensive technical efficiency, single technical efficiency, and efficiency of only considering the scale. The model used in this paper is based on the DEA model with input as the main influencing factor. The model adopted by the research in this paper is DEA model with input as the main influencing factor. The software used for accurate calculation is DEA-Solver Pro5.0. These efficiency scores in this region are calculated from the two cases of variable compensation scale. 


\subsubsection{Efficiency calculation results}

(1) Comprehensive technical efficiency

In the case of the most output, the cost of the decision-making unit can meet the minimum factor requirement. It can be used to indicate whether the industrial structure can meet the requirements of comprehensive benefits, and whether it can obtain the maximum economic and social benefits. It can measure the overall efficiency of the decision-making unit, and it can also reflect whether the cost of public cultural construction has been wasted.

This paper uses the average level of efficiency scores of the six provinces in the central region from 2013 to 2017 to indicate the public finance expenditure efficiency, the numerical range is between 0.384 and 0.432 , and both are below 0.5 , the efficiency value is low. It shows that the investment in public cultural service resources in the central region is seriously wasted, and nearly $67 \%$ of the input resources have not been effectively utilized. At the same time, the table also reflects that the comprehensive technical efficiency of the central region is growing slowly in the fluctuations, showing an upward trend, indicating that there is still room for improvement in the efficiency of fiscal expenditure in the central region.

Table 3 Comprehensive technical efficiency of public cultural service expenditures in the central region from 2013 to 2017

\begin{tabular}{lllllll}
\hline Province & 2013 & 2014 & 2015 & 2016 & 2017 & Average \\
\hline Shanxi & 0.186 & 0.164 & 0.155 & 0.100 & 0.150 & 0.151 \\
Anhui & 1 & 0.819 & 0.794 & 0.766 & 1 & 0.876 \\
Jiangxi & 0.280 & 0.240 & 0.200 & 0.159 & 0.173 & 0.210 \\
Henan & 0.625 & 0.803 & 0.725 & 0.971 & 0.921 & 0.809 \\
Hubei & 0.220 & 0.204 & 0.208 & 0.144 & 0.124 & 0.180 \\
Hunan & 0.263 & 0.230 & 0.223 & 0.235 & 0.226 & 0.235 \\
Average & 0.429 & 0.41 & 0.384 & 0.396 & 0.432 & 0.410 \\
\hline
\end{tabular}

(2) Pure technical efficiency

The pure technical efficiency can be calculated by the BBC model under the assumption that the scale returns are variable. It shows that when the scale is constant and the output is the largest, the cost of the decision-making unit can obtain the minimum standard factor expected. This indicator can directly reflect the extent to which the government's fiscal expenditure is affected by technological backwardness. It can also be used to measure whether the local government can reasonably control the expenditures to meet the budget when the government's financial input costs for public affairs and culture remain unchanged.

The empirical calculation results show that the average level of the pure technical efficiency scores in the central region from 2013 to 2017 is 0.661 . It can be seen from the table that the pure technical efficiency score of the central region is higher in the past five years, larger than 0.5, but there is still a phenomenon of waste of resources. It can be seen from the table that the efficiency of pure technology in the central region shows a significant change, which is gradually decreasing and may continue. 
Table 4 2013-2017 Central Public Cultural Service Government Pure Technical Efficiency

\begin{tabular}{lllllll}
\hline Province & 2013 & 2014 & 2015 & 2016 & 2017 & Average \\
\hline Shanxi & 0.415 & 0.388 & 0.390 & 0.304 & 0.281 & 0.356 \\
Anhui & 1 & 0.819 & 0.869 & 0.804 & 1 & 0.898 \\
Jiangxi & 0.851 & 0.760 & 0.661 & 0.542 & 0.537 & 0.670 \\
Henan & 0.943 & 0.902 & 0.915 & 1 & 1 & 0.952 \\
Hubei & 0.628 & 0.567 & 0.522 & 0.374 & 0.306 & 0.479 \\
Hunan & 0.789 & 0.697 & 0.625 & 0.528 & 0.425 & 0.613 \\
Average & 0.771 & 0.689 & 0.664 & 0.592 & 0.592 & 0.661 \\
\hline
\end{tabular}

(3) Scale efficiency

After investing a certain amount of capital, the maximum output of production using current technology is divided by the value of the output under optimal planning conditions. This is scale efficiency. It can be used to feedback the extent to which the industry scale affects the output units, so that the industrial structure can be better adjusted. The larger its value, the better its production scale and the closer to the optimal situation, so the scale efficiency can be used to judge whether the expenditure for public cultural construction can be classified into the optimal production scale.

Table 5 Government-scale efficiency of public cultural services in the central region from 2013 to 2017

\begin{tabular}{lllllll}
\hline Province & 2013 & 2014 & 2015 & 2016 & 2017 & Average \\
\hline Shanxi & 0.448 & 0.423 & 0.397 & 0.329 & 0.534 & 0.426 \\
Anhui & 1 & 1 & 0.914 & 0.953 & 1 & 0.973 \\
Jiangxi & 0.329 & 0.316 & 0.303 & 0.293 & 0.322 & 0.313 \\
Henan & 0.663 & 0.890 & 0.792 & 0.971 & 0.921 & 0.847 \\
Hubei & 0.350 & 0.360 & 0.398 & 0.385 & 0.405 & 0.380 \\
Hunan & 0.333 & 0.330 & 0.357 & 0.445 & 0.532 & 0.399 \\
\multicolumn{1}{c}{ Average } & 0.521 & 0.553 & 0.527 & 0.563 & 0.619 & 0.556 \\
\hline
\end{tabular}

According to the data in the table, between 13 and 17 years, the scale efficiency of fiscal expenditures for public facilities and cultural construction in the central region has increased. The regional average is the scale of the region. The efficiency is 0.556 , which is lower than the average technical efficiency average of 0.661 , indicating that the scale of production has not yet reached the best state, and it can also have a large increase.

\subsubsection{Analysis of results}

Table 4.5 2013-2017 Central Region Public Cultural Services Scale Income Status

\begin{tabular}{llllll}
\hline province & 2013 & 2014 & 2015 & 2016 & 2017 \\
\hline Shanxi & invariant & invariant & invariant & invariant & decline \\
Anhui & invariant & decline & increasing & decline & invariant \\
Jiangxi & invariant & invariant & invariant & invariant & invariant \\
Henan & invariant & increasing & increasing & increasing & decline \\
Hubei & invariant & invariant & invariant & invariant & invariant \\
Hunan & invariant & invariant & invariant & invariant & invariant \\
\hline
\end{tabular}


According to the annual data, the provinces with effective public cultural service expenditures in the central region from 2013 to 2017 are only in Anhui Province. In 2013 and 2017, TE=1, they are on the production frontline, and the efficiency shown in the technology and scale is effective, reaching DEA efficiency. In other years, there are no provinces with valid DEA, indicating that the overall level of overall efficiency of government spending on public cultural services in the central region is consistently low. From the annual data, we can also know the years when the effective expenditure is small, and the average expenditure efficiency may be high. Therefore, it has also proved that the results of the province's efficiency have remained unchanged, and the distribution of fiscal and cultural service expenditure efficiency varies among regions. According to the annual average expenditure efficiency, when the average efficiency data of the central region fluctuates around 0.4, it indicates that the overall cultural service financial expenditure resources of the central region have not been maximized, and about $60 \%$ of the investment has not been utilized. At the same time, there are also diminishing returns to scale in the past three years, indicating that the scale of individual government expenditures in the central region is too large. Therefore, in order to increase the efficiency of fiscal expenditure scale, local governments need to The scale of public cultural expenditures is rationalized and controlled. For the provinces that are in the stage of increasing scale and income, the scale of public cultural services is not reasonable. At the same time, in order to have a high proportion of returns, it is necessary to increase investment, so as to increase the amount of all input resources in the same proportion. This proves that at this time, if we want to promote the development of cultural undertakings and improve the efficiency of fiscal expenditure, we should raise the expenditure on public cultural finance.

\section{Conclusion}

This paper focuses on the fiscal expenditure efficiency of public cultural services in the central region. Domestic research is mainly aimed at the national expenditure efficiency evaluation, and the lack of research on the efficiency of a region or regions, and this article is from the perspective of regional, only to evaluate the efficiency of public culture in the central of China, this can be more comprehensive and detailed reflect the efficiency of various provinces differences between regions and internal imbalance problem, is advantageous to the targeted to solve the problem of the low efficiency of the provinces in central China. Secondly, a relatively comprehensive index system was selected. From the construction of input and output index of DEA model to the selection of efficiency influencing factors, it achieved the objective and reliability based on actual conditions. Finally the empirical results obtained are analyzed in detail, found that the public culture of spending efficiency under the influence of various factors such as society, economy, policy, and according to the provinces in central China's actual situation of the public cultural offer, put forward the corresponding policies and Suggestions, in order to improve the culture of the local government service level, to improve the situation of low efficiency of the central region. In this way, we can promote the equalization of public culture so that all the people can enjoy the fruits of deepening cultural reform and enrich their spiritual needs.

\section{References}

[1] Aaberge R, Langørgen A. Measuring the benefits from public services: The effects of local government spending on the distribution of income in Norway [J]. Review of Income and Wealth, 2006, 52(1): 61-83.

[2] TI-FU A. On Improvement of Public Finance System and Realization of Public Service Equalization [J]. Research on Financial and Economic Issues, 2007, 7:000.

[3] Qian J. Improving Policy Design and Building Capacity in Local Experiments: Equalization of Public Service in China's Urban-rural Integration Pilot [J]. Public Administration and Development, 2017, 37(1): 51-64.

[4] Yi-hua L. Study on Equalization of Basic Public Service in Urban and Rural Areas [J]. Taxation and Economy, 2008, 
4: 007.

[5] Li B, Li T, Yu M, et al. Can equalization of public services narrow the regional disparities in China? A spatial econometrics approach [J]. China Economic Review, 2017, 44: 67-78.

[6] Jian-dong Y I. A study of sports public services in China [J]. Journal of Physical Education, 2012, 2: 002.

[7] JIANG X, SHE L. Public welfare and market, a choice to make about the approach to the construction of public culture [J]. Journal of Guangzhou University (Social Science Edition), 2006, 8: 012.

[8] Kim S. National culture and public service motivation: investigating the relationship using Hofstede's five cultural dimensions [J]. International Review of Administrative Sciences, 2017, 83(1_suppl): 23-40. 